\title{
Location Management System based RFID and Google Earth API
}

\author{
Basheera M. Mohmmod \\ Computer Engineering Dept. \\ College of Engineering \\ University of Baghdad
}

\author{
Sadiq H. Abdulhussain \\ Computer Engineering Dept. \\ College of Engineering \\ University of Baghdad
}

\author{
Akeel A. Mohammed \\ Electronic and Communication \\ Engineering Department. \\ College of Engineering \\ University of Baghdad
}

\begin{abstract}
Recently many applications need location management systems in their work to determine the location of humans and objects. The work in this paper is going to make a combination between two technologies; Radio Frequency Identification (RFID) technology and computer systems technology with the using of Google earth API. In this paper the movement of persons and objects can be detected through using RFID system and Google earth API then the information of these persons or objects such as place and time are recorded in a database to be used another time in specific applications. This system can be used in many different places such as tracing and tracking the movement of persons in colleges, hospitals, banks and other places, therefore, it is consider a useful system in determining the location of objects, tracing, tracking, making security and other applications.
\end{abstract}

\section{Keywords}

Location Management System Based RFID and Google Earth API.

\section{INTRODUCTION}

The 18th century was the epoch of Industrial Revolution and great mechanical systems, the 19th century was considered as the era of steam engine, and the 20th century witnessed the appearance of the important technology of information gathering, processing, and distribution [1]. As a result of the increasing complexity, and modernization of life, it is necessary to develop and enhance the life styles in all of its branches. Many branches appear to fulfill the demands of modernizing and digitizing like the Information and Communication Technology (ICT), distributed system, networking, automated system and automatic identification technology [2]. Auto-ID technology grows to be very accepted in various branches of life. There are many types of these technologies like RFID (Radio Frequency Identification), barcode system, optical character recognition, smart cards, voice identification and finger print procedure as shown in Figure 1. The Auto-ID can track enterprise worldly goods and the movement of persons, products, vehicles and other assets across big geographic areas.

RFID considers one of the most greatest and important technologies in the recent years. A combination between RFID technology, computer systems and some programs (such as Google Earth API) will provide necessary storage and computing capabilities as standardized services over wide application areas

\section{RFID TECHNOLOGY}

RFID is an electronic and wireless sensor technology which is based on the detection of electromagnetic signals. RFID is a very important technology and business tool that has come of age, and holds the promise of replacing existing identification technologies like the barcode and becomes king of the hill [3]

\subsection{History of RFID}

The roots of RFID technology can be traced back to World War II as it's generally said [4].

\subsection{What is RFID}

RFID refers to small electronic devices that consist of a small chip and an antenna. This system uses tags attached to the objects to be identified. Interrogators or readers send a signal to the tag and read its response [5]. The readers in turn transmit the received data to a computer system running RFID software to manage it.

\subsection{Components of RFID}

RFID System components can be classified into two types:

- Hardware components.

- Software components.

Hardware components: There are three part of RFID hardware components that can be divided as follows [5]:

\section{1- The Tag:}

The first part of RFID system is the tag which is a microchip joint with an antenna; it contains the identification number. The packaging structured of RFID tag enables it to be attached to an object to be tracked [3]. Some types of RFID Tag are shown in the Figure 2.

\section{2- RFID Reader:}

The second part of RFID system is the reader which is also called interrogator. It is a device that gathers information from tags and sends data to the host computers which have the software application. The reader has an antenna that emits radio waves. Figure 3 shows a specific circuit of RFID Reader.

\section{3- The antenna:}

The antenna of the reader used for communication between the reader and the tag. It is physically attached to the reader at one of its antenna ports by a cable [3]. It is determining the coverage zone, range and accuracy of communication. For example, a linear reader antenna offers a higher range than a circular reader antenna. The size and shape of the antenna typically determines the limits of the dimensions of the entire tag packaging.

The Software components:

The software components of RFID system are composed of the following three main parts [5]:

\section{1- RFID middleware:}

It is a group of software that acts as a bridge between RFID system components and host applications. 


\section{2- RFID system software:}

This collection is a set of software necessary to make the basic interaction between tag and reader.

\section{3- Host application:}

It is an earlier presented software program in an enterprise, such as a warehouse management system and an inventory control system. It takes the data from a reader via RFID middleware to process and handle.

\section{GOOGLE EARTH}

Google Earth is a virtual map, globe and geographical information program and it is enable scientists around the world to data communicate and findings in an intuitive threedimensional (3D) global that was originally called Earth Viewer 3D [6]. Virtual globes are low cost and easy to use in data collection, exploration and visualization It maps the Earth by the superimposition of images taken from satellite imagery [6].

Google Earth makes us travel through a virtual globe and view satellite imagery,3D buildings, terrain, maps. The options within Google Earth are endless, such as discover the earth, jump in the ocean, visit moon and mars, , explore the sky, create custom image and hikes on handheld GPS devices [7]. Google Earth are adopting in the classroom by teachers for lesson planning, like teaching geographical themes [7].

\subsection{Coordinate System and Projection}

A geographic coordinate system (GCS) defines locations on the earth using a three-dimensional spherical surface. Every location on the Earth can be specified by a set of numbers using GCS [ 8]

\subsubsection{Latitude:}

It is an imaginary circle they are total 180 . In the spherical system, 'horizontal' or east-west lines are lines of equal latitude or parallels i.e. the lines joining points of the same latitude trace circles on the surface of Earth [8].

\subsubsection{KML File:}

All information and coordinates which Google Earth deal with it they are created in KML file using JavaScript and iFrames. KML is standard for Keyhole Markup Language .

KML is used to display geographic data in an Earth browser such as Google Earth and Google Maps, it is a file format. It uses a tag-based structure with nested elements and attributes, i.e. these files are XML-based scripting files; require the use of an extremely verbose tag-based language [9].

KML fields:

KML uses common XML types such as string, Boolean, double, integer, and float. Besides, it defines types of field element [10].

\section{SYSTEM DESIGN AND WORK}

The design of the system consists of a combination between hardware and software connected as in the block diagram shown in Figure 4.The first part of the system work depends on the work of the RFID, which is an electronic device consists of RFID reader, antenna and tag. The RFID reader reads the tag number (ID associated to a individual person) when the tag being in the coverage zone of the reader antenna, then RFID reader sends this information to the computer (PC), the software program in the computer takes this information then updates it's Database and sends the (longitude/ latitude) to the Google Earth program. When Google Earth receives (longitude/ latitude) it finds the person location then displays that location on the screen of the that computer. The flowchart for the system software as shown in Figure 5 .

\section{THE IMPLEMENTATION OF THE SYSTEM}

The implementation of the system is done as discussed in the sections below:

\subsection{TTL to RS232 converter}

The output voltage level from RFID is the TTL level but the pc is used the RS232 voltage level. For the above reason we must use the TTL to RS232 Converter.

\subsection{The implementation of the converter circuit from TTL to RS232 level}

At this implementation the IC MAX232 and a serial connector (known as DB9 connector) will be used as shown in the Figure 6.

\subsection{TTL to serial USB used in the implementation}

For simplification, the implementation of this system is done by using a TTL to Serial USB connector. This item is a RS232 to TTL converter IC with connectors. It allows any TTL level UART to connect to the standard RS232 levels of a serial port through USB port [11].

It can be powered from $3 \mathrm{~V}$ to $5.5 \mathrm{~V}$ and meets ElA/TIA-232 and V.28/V.24 specifications, even at VCC $=3 \mathrm{~V}$ [11].

\subsection{RFID used in the implementation of the system}

In this system low frequency RFID with $125 \mathrm{KHz}$ is used. It is can provide a distance about 50 millimeters.

The Specification and Parameter of this type of RFID is shown in Table 1.

\subsection{The programming languages used in the system:}

To complete implementation of this system we use the Following programming language:

\subsubsection{Visual basic:}

It is the main language used in this system. It is join the implementation of the hardware with the software. (include all the programming languages used in this system) and display the result in GUI form.

\subsubsection{Database:}

This system need a Database system to store, update information, etc we use Microsoft office access .

\subsubsection{Java script :}

We use java script language to manage Google earth API Also to control and change the setting of required features and how to display it.

\subsubsection{Google Earth API :}

Google Earth API standard for Google earth application programming interface.

The Google Earth applications can be embedded into web pages by using Google Earth API with JavaScript code. With this API plug in installed, the applications can work interactively in web browsers [6]. Developers who create web pages with the Google Earth API need to get a Google Maps key to specify in the code for these pages. The also need to 
write JavaScript code to implement the Google Earth API applications in the web pages. In order to run the applications in browsers, developers and end users need to install the Google Earth plugin. The API can display lines, placemarks, overlays, polygons, and 3D models on the imagery [6].

\subsection{System Hardware Implementation}

The system was implemented and all component of the system were connected, and then tested inside the University of Baghdad. The implementation is as shown in the Figure 7.

We put the RFID Reader in the intended location and give to the person (students or lecturers or staff) the RFID Tag. The working steps of the system are defined as follows:

\section{1- Display the location of the current/dedicated person}

When the person who carries the Tag move in the location which contained the RFID Reader its position will be displayed as shown in Figure 8.

\section{2-So the Data Base will be update in the same time}

In addition to display the position of the current person, the exact time and date of person's existence in that position and other information of this person will be recorded in the data base. As shown in the Figure 9.

\section{3- Adding information for unknown Tag:}

When there is new Tag (in this case there is no information yet), it's position will be displayed and the new record will be inserted in the Data Base also the administrator can define this new unknown Tag by enter it's information. This explain in the following Figure10 and Figure 11 ,this unknown Tag because there is no information, we can add information by click this button and the window will be appear as shown in Figure 11.

4- Searching for any person and show the information dedicated to himlher:

We can show the information about any person we need, take care that the person must have Tag ID and an information recorded in the Data Base. As shown in the Figure 12.

\section{CONCLUSION}

This system has multiple features since it is consider a location management system because it has the ability to provide the accessibility of any person or object has tag ID that make the operation of tracing simple by finding the first and last place of that person or object. Also this system has the ability for searching for any person/object and adding information to unknown tag. From the other side, this system enhances the security of the locations specially the governmental locations like Universities, Banks, Offices, etc. because it gives information about the person movement to this places.

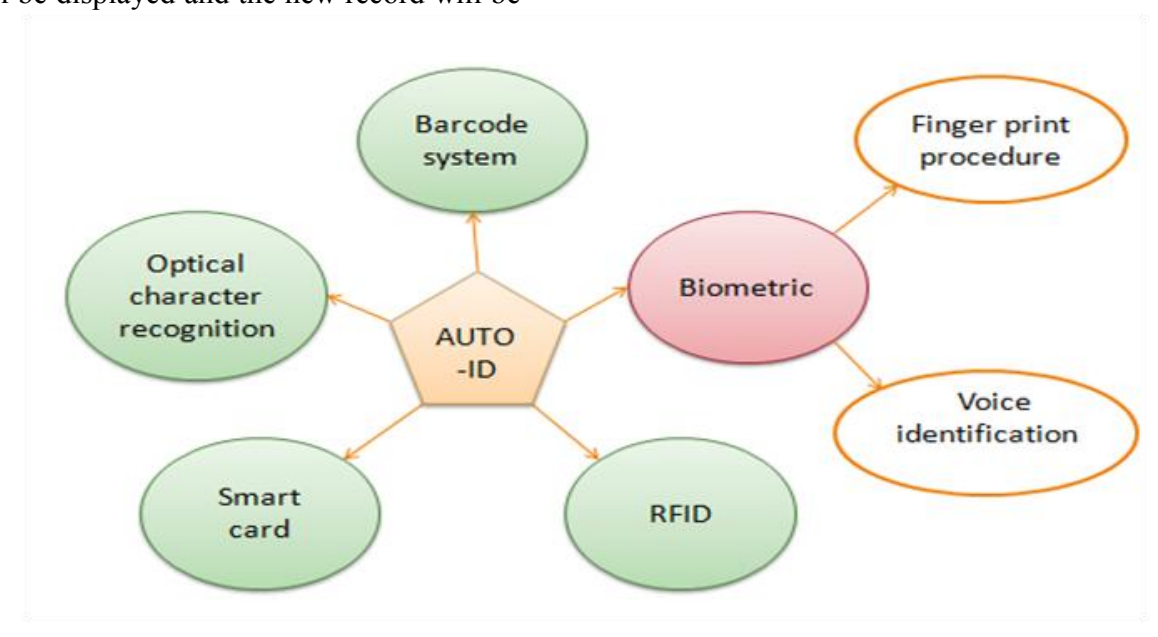

Fig 1: Types of Auto-ID Technology [5]

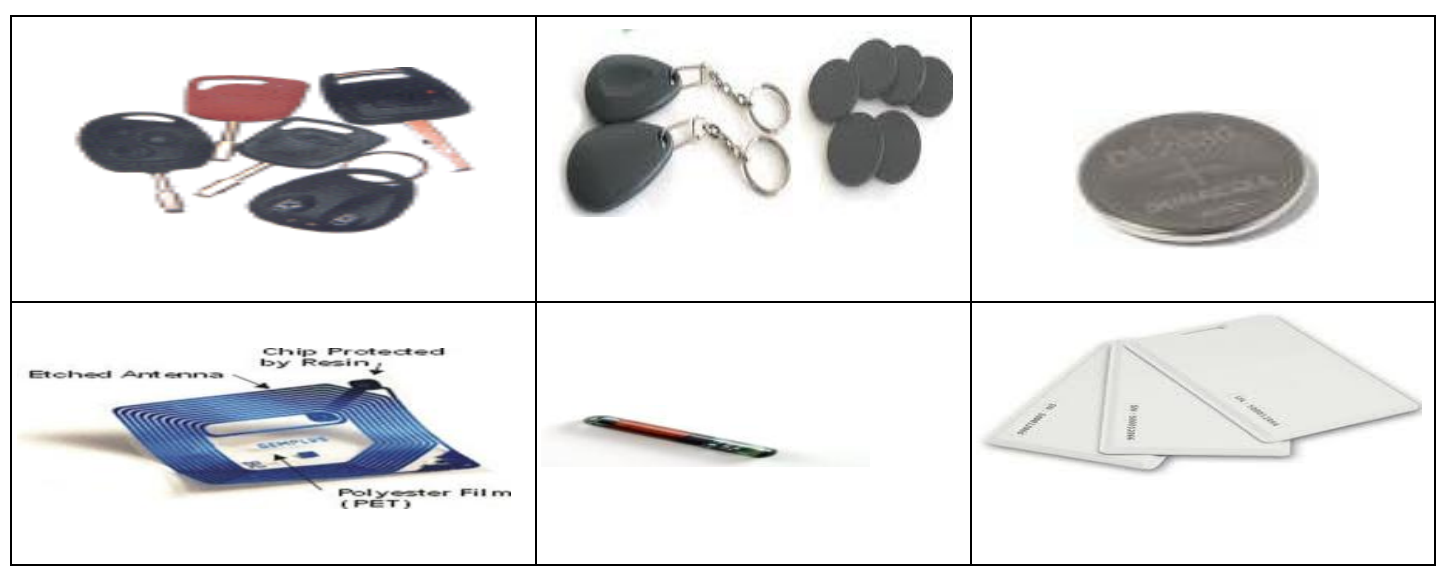

Fig 2: Some Types of RFID Tag. 


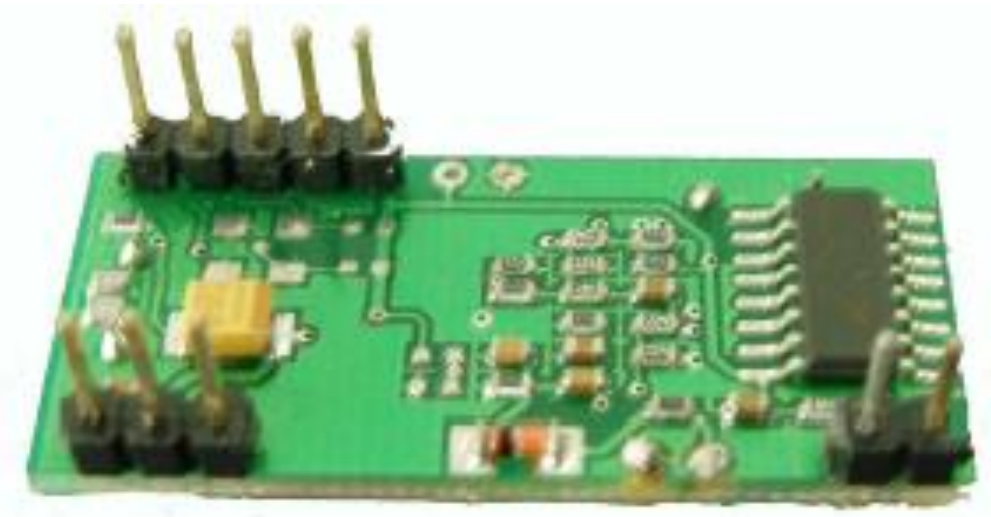

Fig 3: RFID Reader

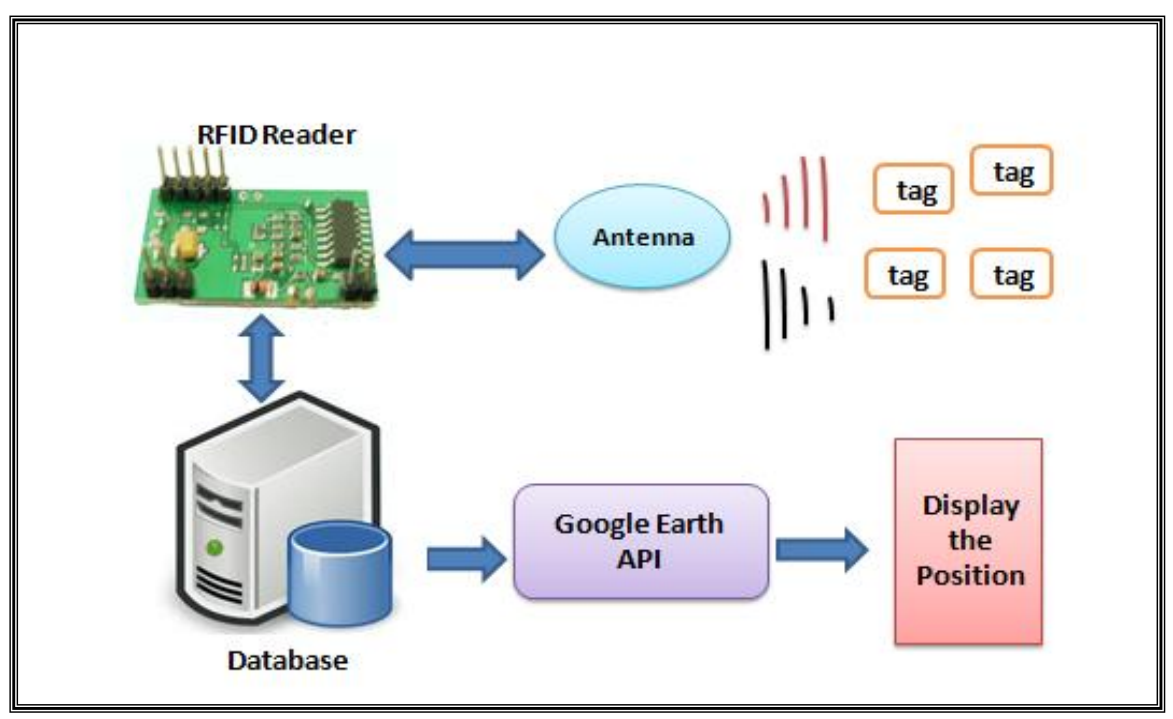

Fig 4: Block Diagram of the System 


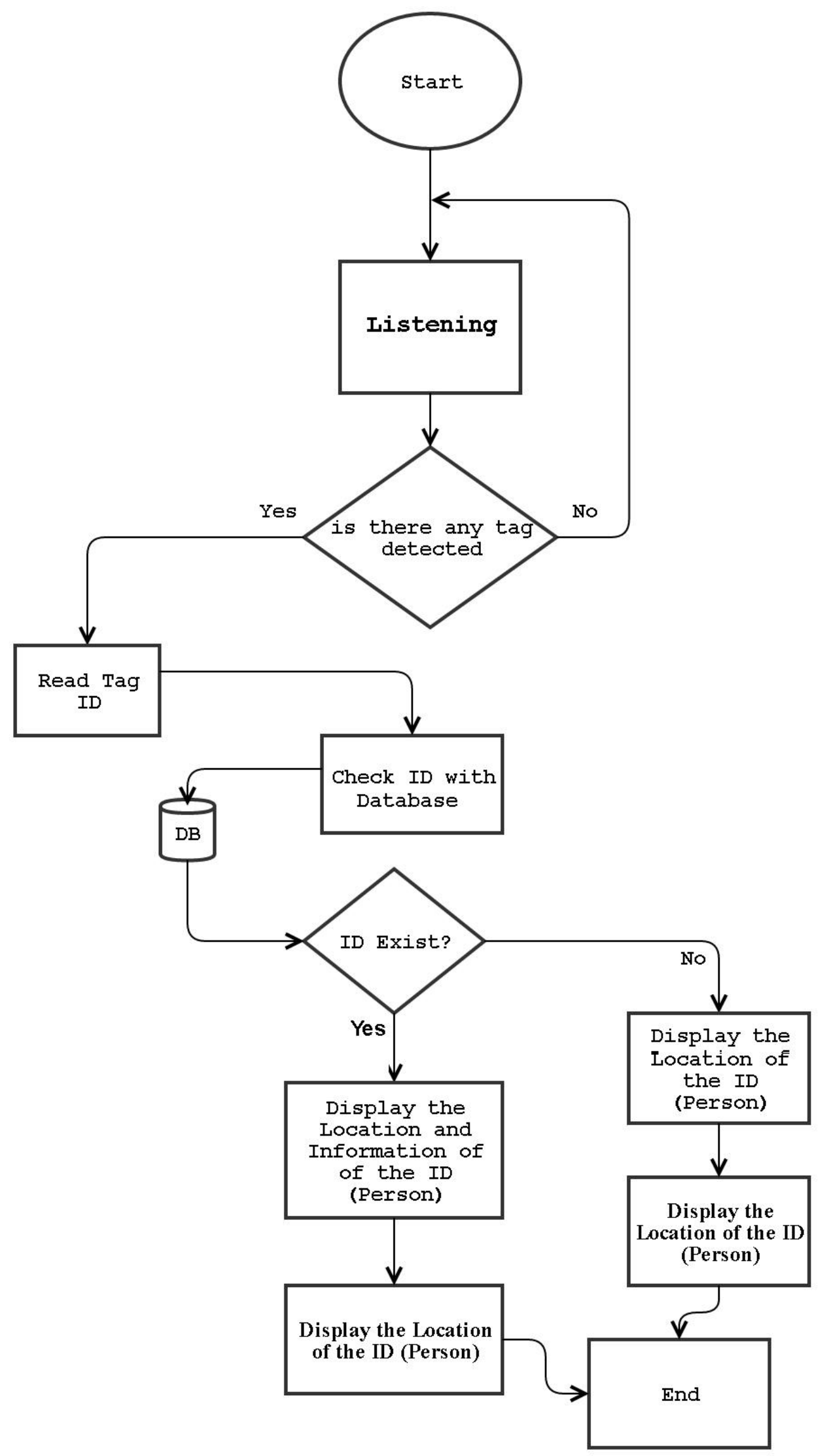

Fig 5: Flowchart of the System 
TTL-RS232-1

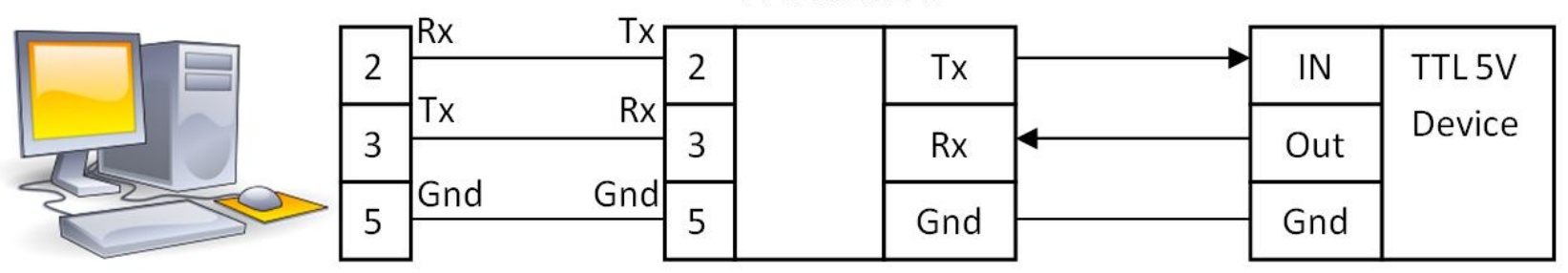

PC or DTE

Fig 6: TTL to RS232 converter

Table 1: Specification of low frequency RFID with $125 \mathrm{KHz}$ [12]

\begin{tabular}{|l|l|}
\hline Frequency & $125 \mathrm{KHz}$ \\
\hline Baud Rate & 9600 ( TTL Electricity Level RS232 format \\
\hline Interface & Weigang26 Or TTL Electricity Level RS232 format \\
\hline Power supply & DC 5V $(+5 \%)$ \\
\hline Current & $<50 \mathrm{Ma}$ \\
\hline $\begin{array}{l}\text { Operating } \\
\text { Range }\end{array}$ & $>50 \mathrm{~mm}($ Depend on Card/Tag shape, manufacturer $)$ \\
\hline $\begin{array}{l}\text { Expand I/O } \\
\text { port }\end{array}$ & N/A \\
\hline $\begin{array}{l}\text { Indication } \\
\text { Light }\end{array}$ & N/A \\
\hline Working temperature & $-10 \mathrm{c}^{0} \sim+70 \mathrm{c}^{0}$ \\
\hline Storage temperature & $-20 \mathrm{c}^{0} \sim+80 \mathrm{c}^{0}$ \\
\hline Max. humidity Relative humidity & $0 \sim 95 \%$ \\
\hline Size & $38.5 \mathrm{~mm} \times 19 \mathrm{~mm} \times 9 \mathrm{~mm}$ \\
\hline
\end{tabular}

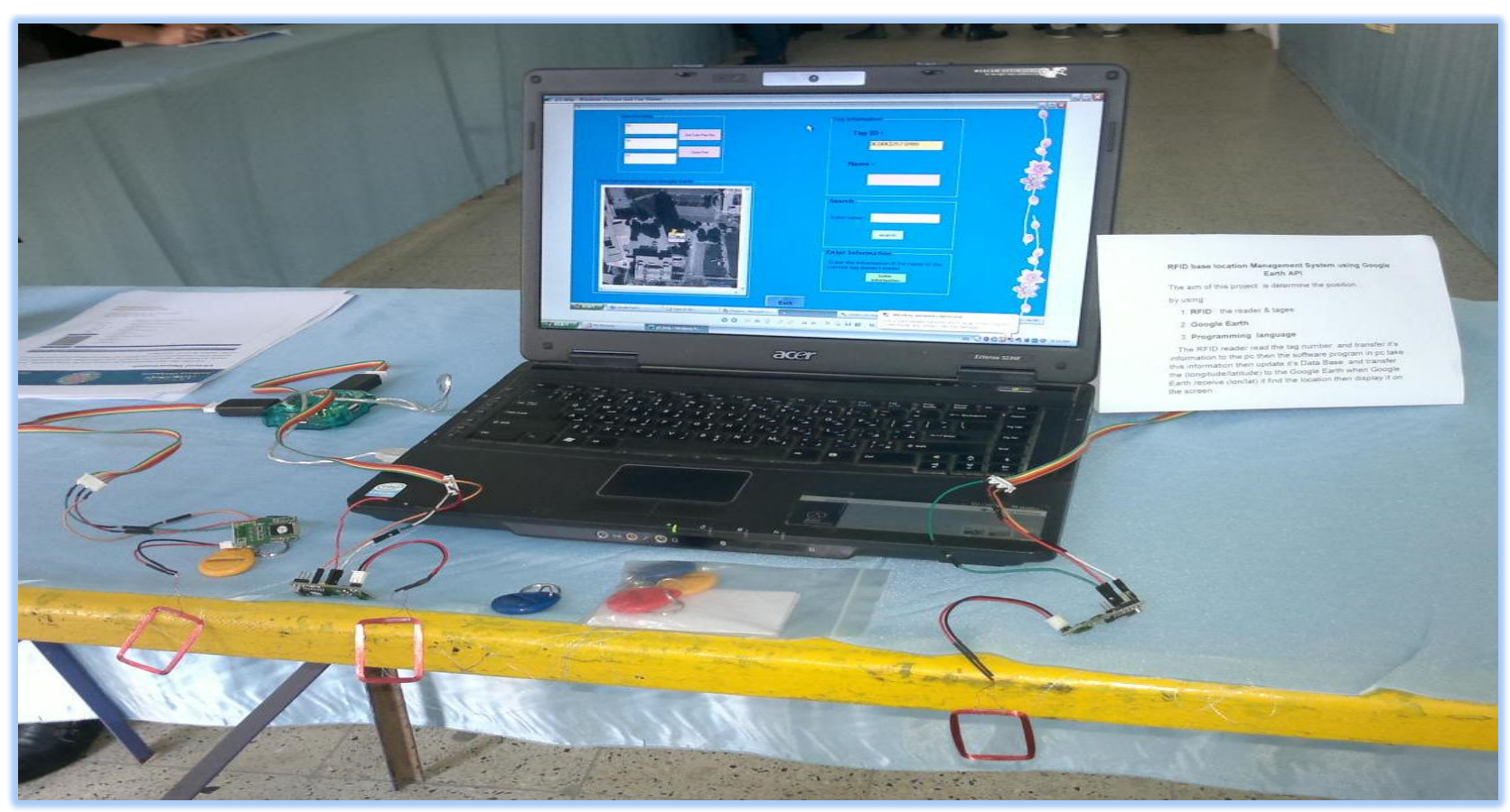

Fig 7: Implementation of the System 


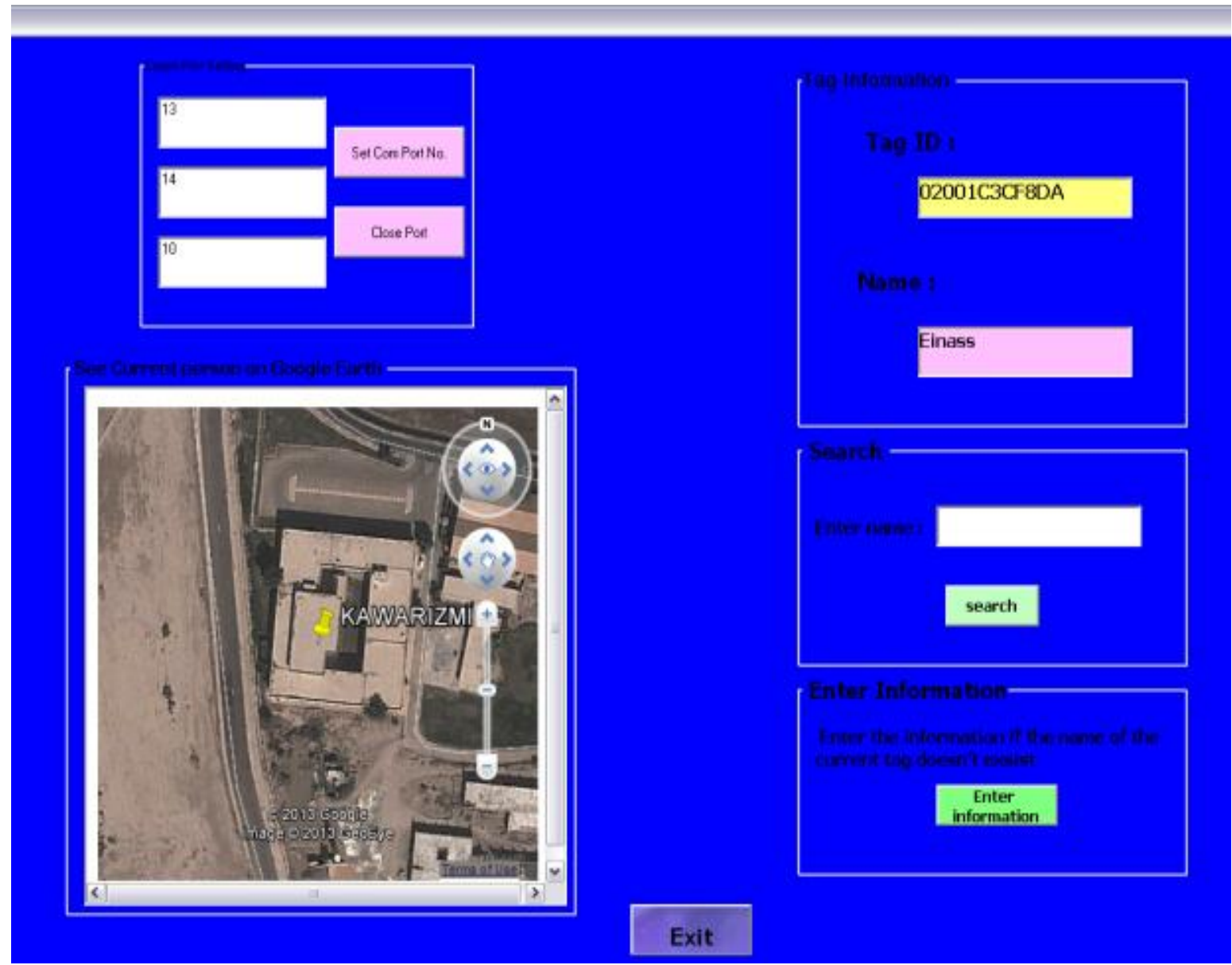

Fig 8: GUI of Display the location of the object

\begin{tabular}{|c|c|c|c|c|c|c|c|c|c|}
\hline \multicolumn{10}{|c|}{$\square$ Information : Table } \\
\hline & ID & Tag_ID & Name & Reader & Lon & Lat & position & Date & Time \\
\hline$\nabla$ & & 102001C42AFF3 & NOOR & & 133.271354 & 44.372309 & kawarizmi & $24 / 1 / 2013$ & $6: 57: 59 \mathrm{PM}$ \\
\hline & & 2 02001C3CF8DA & Einass & & 233.272978 & 44.374101 & Architecture En & $24 / 1 / 2013$ & 6:58:05 PM \\
\hline & & $301002 \mathrm{DC} 836 \mathrm{D} 2$ & Sadiq & & 133.271354 & 44.372309 & kawarizmi & $24 / 1 / 2013$ & 6:58:11 PM \\
\hline & & 502001 C42AFF3 & NOOR & & 233.272978 & 44.374101 & Architecture En & $24 / 1 / 2013$ & 6:58:17 PM \\
\hline & & $601002 \mathrm{DC} 836 \mathrm{D} 2$ & Sadiq & & 133.271354 & 44.372309 & kawarizmi & $24 / 1 / 2013$ & 6:58:21 PM \\
\hline & & $801002 \mathrm{DC} 836 \mathrm{D} 2$ & Sadiq & & 233.272978 & 44.374101 & Architecture En & $25 / 1 / 2013$ & 9:04:43 PM \\
\hline & & 17 3C00CE891962 & & & 133.271354 & 44.372309 & kawarizmi & $25 / 1 / 2013$ & 9:48:58 PM \\
\hline & & 18 280077E60EB7 & & & 233.272978 & 44.374101 & Architecture En & $25 / 1 / 2013$ & 10:07:39 PM \\
\hline & & 22 28005A261E4A & & & 133.271354 & 44.372309 & kawarizmi & $5 / 2 / 2013$ & 12:10:22 PM \\
\hline & & 25 3C00CE891962 & huda & & 133.271354 & 44.372309 & kawarizmi & $5 / 2 / 2013$ & 12:13:42 PM \\
\hline & & 29 3C00CE891962 & huda & & 133.271354 & 44.372309 & kawarizmi & $5 / 2 / 2013$ & 12:19:14 PM \\
\hline & & 35 280077E60EB7 & yasser & & 233.272978 & 44.374101 & Architecture En & $5 / 2 / 2013$ & 12:24:28 PM \\
\hline & & 36280077 E60EB7 & yasser & & 133.271354 & 44.372309 & kawarizmi & $5 / 2 / 2013$ & 12:24:56 PM \\
\hline & & $3902001 \mathrm{C}^{2} \mathrm{CF} 8 \mathrm{D} A$ & Einass & & 233.272978 & 44.374101 & Architecture En & $5 / 2 / 2013$ & 12:27:31 PM \\
\hline & & 4002001 C42AFF3 & NOOR & & 133.271354 & 44.372309 & kawarizmi & $5 / 2 / 2013$ & 12:28:26 PM \\
\hline & & $4101002 \mathrm{DC} 836 \mathrm{D} 2$ & Sadiq & & 233.272978 & 44.374101 & Architecture En & $5 / 2 / 2013$ & 12:29:29 PM \\
\hline & & 42 02001C42AFF3 & NOOR & & 233.272978 & 44.374101 & Architecture En & $5 / 2 / 2013$ & 12:35:11 PM \\
\hline & & $4301002 \mathrm{DC} 836 \mathrm{D} 2$ & Sadiq & & 133.271354 & 44.372309 & kawarizmi & $5 / 2 / 2013$ & 12:38:10 PM \\
\hline & & 4602001 C 3 CF8D $A$ & Einass & & 133.271354 & 44.372309 & kawarizmi & $5 / 2 / 2013$ & 12:48:37 PM \\
\hline & & $4801002 \mathrm{DC} 836 \mathrm{D} 2$ & Sadiq & & 233.272978 & 44.374101 & Architecture En & $5 / 2 / 2013$ & 1:00:20 PM \\
\hline & & $5001002 \mathrm{DC} 836 \mathrm{D} 2$ & Sadiq & & 133.271354 & 44.372309 & kawarizmi & $5 / 2 / 2013$ & 1:02:22 PM \\
\hline & & 51 02001C42AFF3 & NOOR & & 233.272978 & 44.374101 & Architecture En & $5 / 2 / 2013$ & 5:40:03 PM \\
\hline & & 5202001 C3CF8DA & Einass & & 233.272978 & 44.374101 & Architecture En & $5 / 2 / 2013$ & 5:40:38 PM \\
\hline & & 53 3C00CE891962 & huda & & 133.271354 & 44.372309 & kawarizmi & $5 / 2 / 2013$ & 5:41:02 PM \\
\hline & & 5402001 C3CF8DA & Einass & & 233.272978 & 44.374101 & Architecture En & $6 / 2 / 2013$ & $11: 27: 45$ PM \\
\hline & & $563 \mathrm{C} 00 \mathrm{CD} 571 \mathrm{FBE}$ & & & 233.272978 & 44.374101 & Architecture En & $6 / 2 / 2013$ & 11:27:48 PM \\
\hline & & 58 02001C42AFF3 & NOOR & & 233.272978 & 44.374101 & Architecture En & $6 / 2 / 2013$ & 11:28:42 PM \\
\hline & & 60 02001C42AFF3 & NOOR & & 133.271354 & 44.372309 & kawarizmi & $6 / 2 / 2013$ & 11:29:28 PM \\
\hline 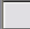 & & 61 3C00CE891962 & huda & & 133.271354 & 44.372309 & kawarizmi & $6 / 2 / 2013$ & 11:30:45 PM \\
\hline 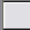 & & $6301002 D C 836 \mathrm{D} 2$ & Sadiq & & 133.271354 & 44.372309 & kawarizmi & $6 / 2 / 2013$ & 11:38:13 PM \\
\hline & & 66 280077E60EB7 & yasser & & 133.271354 & 44.372309 & kawarizmi & $7 / 2 / 2013$ & 12:01:31 AM \\
\hline & (14) 4 & $1 D$ & 102 & & & & & & \\
\hline
\end{tabular}

Fig 9: GUI of the Data Base 


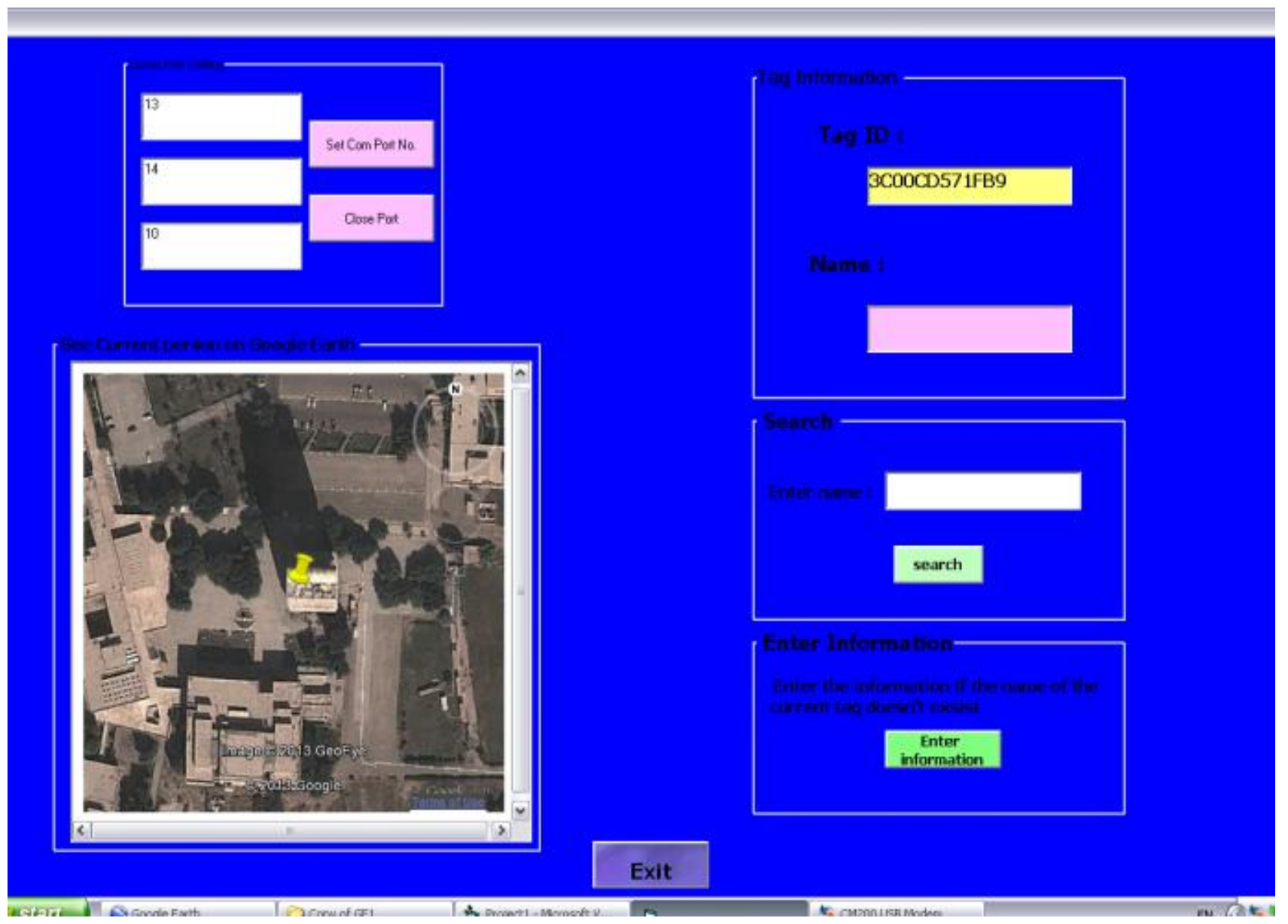

Fig10: GUI for unknown Tag

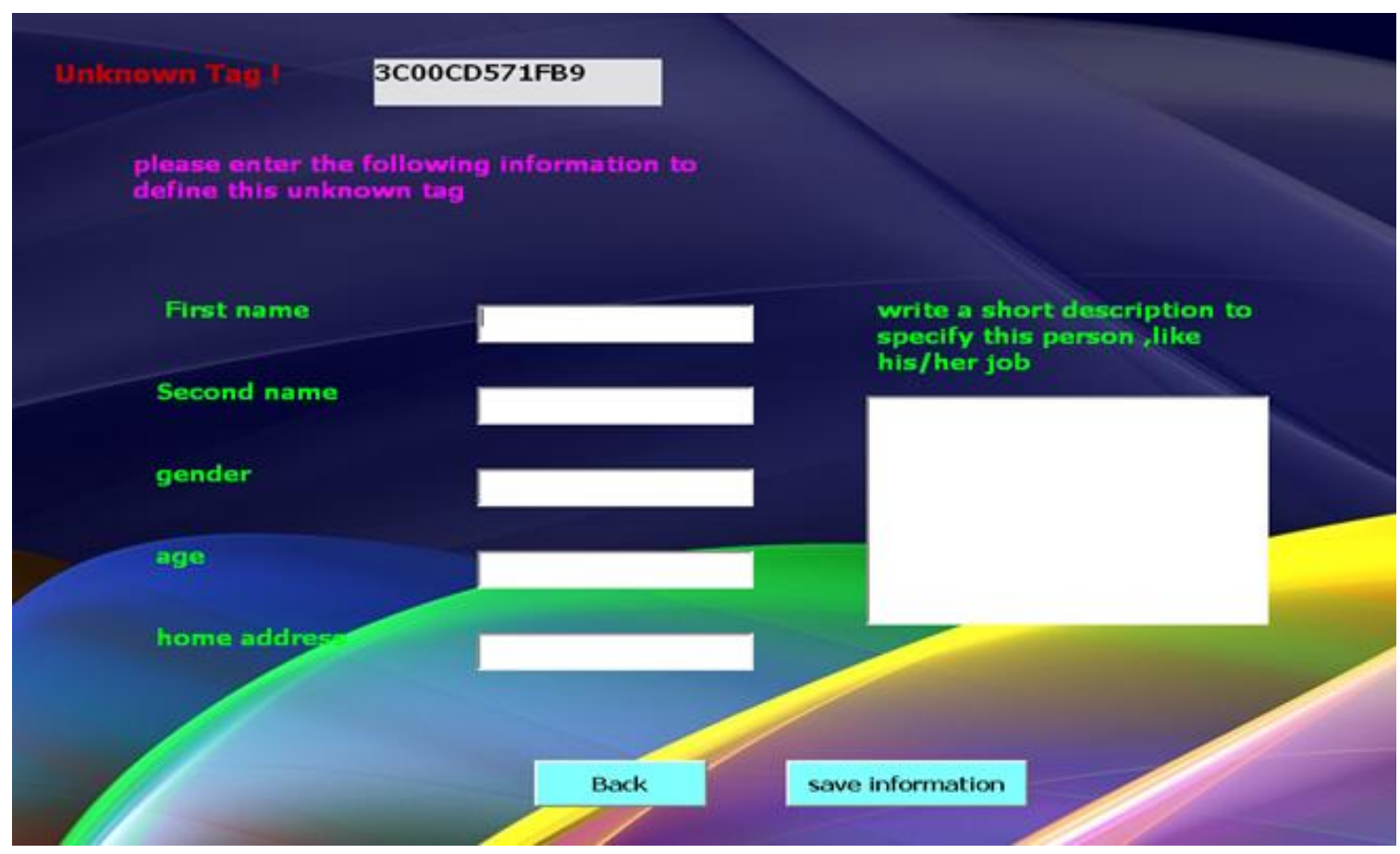

Fig 11: GUI of adding information for new Tag 


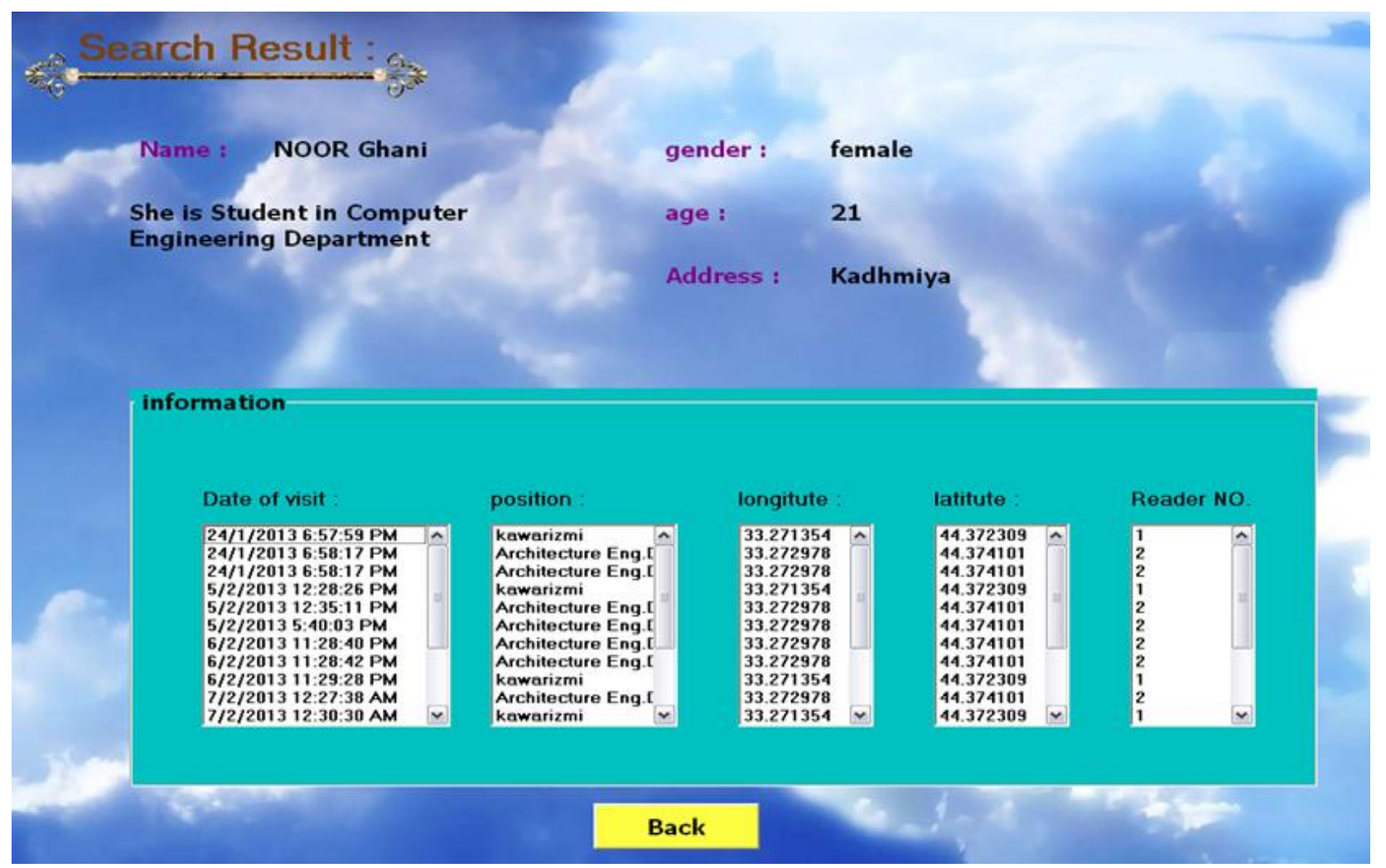

Fig 12: GUI of searching information for any person

\section{REFERENCES}

[1] Tanenbaum A.S., "Computer Networks", Fourth Edition, Prentice Hall, 2003.

[2] Roberti M. "The History of RFID Technology", RFID Journal , 2005.

[3] Sweeney P. J.,"RFID for Dummies", First Edition, Wiley Publishing, Inc, 2005.

[4] Al-Tameemi Z. F. A., "Design and Implementation of a Scalable Automated RFID based Attendance System with Scheduling Technique", M.Sc. Thesis, School of Electrical and Electronic Engineering, University of Science Malaysia, 2011

[5] Mahmood B. M., " CONSTRUCTION OF AN INFRASTRUCTURE FOR RFID SYSTEM", M.Sc. Thesis, University of Baghdad, 2012.

[6] YU L., GONG P., " Google Earth As A Virtual Globe Tool For Earth Science Applications At The Global Scale: Progress And Perspectives", International Journal of Remote Sensing, Vol. 33, No. 12, June 2012.
[7] Schultz R. B. , Kerski J. J. , and Patterson T. C., " The Use of Virtual Globes as a Spatial Teaching Tool with Suggestions for Metadata Stan dards", Journal of Geography, 107:27-34, 2008.

[8] Kennedy M., "Understanding Map Projections", Environmental Systems Research Institute, 2000.

[9] Abdulrahman F.H., " Using KML files as encoding standard to explore locations, access and display data in Google Earth", M.Sc. Thesis, Graduate School of The Ohio State University, 2008.

[10] Santhatam A., "Bike And Running Trails On Android Based On Google Maps API", MS.c. Thesis, San Diego State University, 2013..

[11] Vladimir Y., "RS-232 Recommended Standard Interface between Data Terminal Equipment and Data CircuitTerminating Equipment Employing Serial Binary Data Interchange", Soft Electro, 2009.

[12] Data Sheet, "RDM630 Specification", http://www.eio.com/p-40778-seeedstudio-rfr101a1m125khz-rfid-module-uart.aspx. 